\title{
Joël Blanchard, Louis XI
}

\section{Paola Cifarelli}

\section{OpenEdition}

\section{Journals}

\section{Édition électronique}

URL : http://journals.openedition.org/studifrancesi/5265

DOI : 10.4000/studifrancesi.5265

ISSN : 2427-5856

\section{Éditeur}

Rosenberg \& Sellier

\section{Édition imprimée}

Date de publication : 1 décembre 2016

Pagination : 510-511

ISSN : 0039-2944

\section{Référence électronique}

Paola Cifarelli, « Joël Blanchard, Louis XI », Studi Francesi [En ligne], 180 (LX | III) | 2016, mis en ligne le 01 janvier 2017, consulté le 18 septembre 2020. URL : http://journals.openedition.org/studifrancesi/ 5265 ; DOI : https://doi.org/10.4000/studifrancesi.5265

Ce document a été généré automatiquement le 18 septembre 2020.



Studi Francesi è distribuita con Licenza Creative Commons Attribuzione - Non commerciale - Non opere derivate 4.0 Internazionale. 


\section{Joël Blanchard, Louis XI}

\section{Paola Cifarelli}

\section{RÉFÉRENCE}

JoËL BLANCHARD, Louis XI, Paris, Perrin, 2015, 371 pp.

1 L'étude du règne de Louis XI réalisée par le grand spécialiste de Commynes qu'est J.B. sera désormais un instrument de travail incontournable non seulement pour les historiens, mais aussi pour les littéraires qui souhaitent approfondir la connaissance du milieu politique caractérisant le troisième quart $d u \mathrm{xv}^{\mathrm{e}}$ siècle. Le ton discursif utilisé parfois par l'A. dans son ouvrage ne doit pas induire en erreur sur la profondeur du travail de recherche qui en est à la base, ni sur l'originalité de la perspective choisie; la richesse des données contenues dans la section consacrée aux «Sources et bibliographie» (pp. 307-343) en est la preuve la plus immédiate: en plus du témoignage des chroniqueurs et mémorialistes, l'A. a recours très souvent aux documents d'archives, et particulièrement aux correspondances, officielles et familières, mais il ne néglige non plus le témoignage du théatre contemporain, notamment les moralités, «révélatrices d'un état de l'opinion vis-à-vis du roi défunt» (p.9). Enfin, la documentation relative aux nombreux procès politiques célébrés pendant le règne de Louis XI, et particulièrement celle concernant celui intenté contre Jacques d'Armagnac, permet d'enrichir les connaissances non seulement du système judiciaire, mais aussi de l'empreinte que le roi a donnée à son action politique.

2 La matière est organisée en dix chapitres, qui abordent tous les aspects de l'activité déployée par Louis XI dans l'exercice du pouvoir. Au fil des pages, l'image complexe d'un monarque pragmatique et omniprésent, parfois incohérent et faussement naïf se dessine, ce qui permet de dissiper un certain nombre de stéréotypes généralement associés à sa figure et d'en confirmer d'autres; l'intitulé des différents paragraphes, souvent rédigés sous la forme d'interrogations, témoigne constamment de l'effort pour aller au-delà des idées reçues et de mieux interroger les documents pour cerner la réalité des faits. 
3 Après un rappel précis mais synthétique des «Temps forts du règne» (pp.11-20), l'attention se focalise d'abord sur les contrastes du futur roi avec son père, qui se révèlent fondés sur des motivations d'ordre juridique plus que psychologique tant dans la sphère publique que dans le domaine privé; pareillement, ce sont des motivations d'ordre politique à dominer dans la relation de Louis XI avec ses enfants, avec une attention constante à la «dimension pragmatique, théâtrale, cérémonielle» de ses actions (p. 39). De la sphère familiale, on passe ensuite aux rapports avec les autres princes européens tels qu'ils ont été établis à partir de 1461, année de l'avènement au trône. Les relations tendues avec la maison d'Anjou, puis celles tout aussi difficiles avec la Bourgogne sont examinées avec objectivité, avant de passer aux autres principautés territoriales et enfin aux affrontements avec Jean II d'Alençon et Jean V d'Armagnac, où les notions de clémence royale, d'indignatio et de male grace jouèrent un rôle capital. Ensuite, ce sont les institutions et les cercles de fidélité qui sont analysés, dont le «fonctionnement dynamique» (p. 77) constitue un moyen pour déterminer les lignes de force de la construction politique du monarque. Les conseillers, les transfuges, les membres du Parlement et des assemblées ainsi que les différentes charges institutionnelles, comme celle de chancelier, font l'objet d'une étude visant à étudier les modalités selon lesquelles le roi se rapporte à ces institutions et les raisons qui déterminent ces comportements.

4 L'organisation militaire (chap. V) et les institutions diplomatiques créées par un roi à la fois fasciné et intimidé par les pouvoirs de la diplomatie (chap. VI) montrent clairement l'importance des choix effectués dans la création des offices et dans le choix des hommes, mais aussi la volonté du monarque de plier la diplomatie à ses intérêts personnels par un détournement des rituels et des codes, ainsi que par une improvisation souvent simulée.

5 Si les questions financières sont sans aucun doute «la colonne vertébrale du 'système Louis XI'» (p. 156), les littéraires seront particulièrement sensibles au chapitre consacré au rapport du roi avec la parole et l'écrit (chap. VIII), dans lequel l'A. examine les témoignages directs et indirects sur l'utilisation de la langue, tant à l'oral qu'à l'écrit: les très nombreuses lettres conservées, ainsi que les notations sur la gestuelle, sur les registres utilisés dans les dialogues, sur l'humour et l'invention verbale permettent de conclure que, loin d'être embarrassé, le roi était un «beau parleur, séduisant, sans réserve ni froideur, sachant rendre plus malléables ses interlocuteurs» (p. 186) et qu'il faisait preuve de curiosité intellectuelle, d'estime pour certains humanistes et d'une culture littéraire considérable.

6 Tout aussi intéressant, surtout pour l'utilisation de sources nouvelles, est le chapitre IX, consacré aux rapports de Louis XI avec la justice. Le dernier volet de cette étude est consacré au domaine de la religion, non seulement pour analyser les caractères de sa piété, mais aussi pour mettre en évidence la tolérance du roi et les intersections avec l'action politique. Dans la conclusion, J.B. dresse un bilan en demi-teintes, soulignant l'«entrelacement de naïveté et de prudence, de surprenant et de raisonnable» (p. 257) qui caractérise la personnalité du monarque, ainsi que sa politique à la fois «imprévisible et opportuniste», pragmatique et efficace. «Versatile» comme l'Hadrien de l'Histoire Auguste (p. 261), Louis XI en ressort réévalué, bien que son règne s'insère difficilement dans le temps long de l'histoire. 